The University of San Francisco

USF Scholarship: a digital repository @ Gleeson Library | Geschke Center

Nursing and Health Professions Faculty Research and Publications

2013

\title{
Condom Negotiation across Different Relationship Types by Young Women Engaged in Sex Work in Phnom Penh, Cambodia
}

Lisa Maher

Julie Mooney-Somers

Pisith Phlong

Marie-Claude Couture

University of San Francisco, mcouture@usfca.edu

Serey Serey Kien

See next page for additional authors

Follow this and additional works at: http://repository.usfca.edu/nursing_fac

Part of the Epidemiology Commons

\section{Recommended Citation}

Lisa Maher, Julie Mooney-Somers, Pisith Phlong, Marie-Claude Couture, Serey Phal Kien, Ellen Stein, Anna Juong Bates, Neth Sansothy, Kimberly Page \& on behalf of the Young Women's Health Study Collaborative (2013) Condom Negotiation across Different Relationship Types by Young Women Engaged in Sex Work in Phnom Penh, Cambodia, Global Public Health: An International Journal for Research, Policy and Practice, 8:3, 270-283, DOI:10.1080/17441692.2013.767930 


\section{Authors}

Lisa Maher, Julie Mooney-Somers, Pisith Phlong, Marie-Claude Couture, Serey Serey Kien, Ellen Stein, Anna Juong Bates, Neth Sansothy, Kimberly Page, and Young Women's Health Study Collaborative 


\title{
Condom negotiation across different relationship types by young women engaged in sex work in Phnom Penh, Cambodia
}

\author{
Lisa Maher ${ }^{a},{ }^{,}$, Julie Mooney-Somers ${ }^{a, b}$, Pisith Phlong ${ }^{c}$, Marie-Claude Couture ${ }^{d}$, Serey Phal \\ Kien $^{e}$, Ellen Stein ${ }^{d}$, Anna Juong Bates ${ }^{a}$, Neth Sansothy ${ }^{f}$, and Kimberly Page ${ }^{d}$ on behalf of \\ the Young Women's Health Study Collaborative \\ aKirby Institute for Infection and Immunity in Society, University of New South Wales, Sydney, \\ Australia \\ ${ }^{b}$ Centre for Values, Ethics and the Law in Medicine, University of Sydney, Sydney, Australia \\ 'Department of Archaeology, Royal University of Fine Arts, Phnom Penh, Cambodia \\ dDepartment of Epidemiology and Biostatistics, University of California, San Francisco, CA, USA \\ eCambodian Women's Development Agency, Phnom Penh, Cambodia \\ fNational Institute for HIV, AIDS, Dermatology and STDs, Phnom Penh, Cambodia
}

\begin{abstract}
Cambodia's 100\% Condom Use Programme is credited with an increase in consistent condom use in commercial sexual interactions and a decrease in HIV prevalence among female sex workers (FSWs). There has been little improvement in condom use between FSWs and non-commercial partners, prompting calls for more innovative approaches to increasing condom use in these relationships. To understand why condoms are used or not used in sexual interactions involving FSWs, we examined condom negotiation across different types of relationships. We conducted 33 in-depth interviews with young (15 to 29 years) women engaged in sex work in Phnom Penh. There was an important interplay between the meanings of condom use and the meanings of women's relationships. Commercial relationships were characterised as inherently risky and necessitated condom use. Despite a similar lack of sexual fidelity, sweetheart relationships were rarely construed as risky and typically did not involve condom use. Husbands and wives constructed their sexual interactions with each other differently, making agreement on condom use difficult. The lack of improvement in condom use in FSWs' non-commercial sexual relationships needs to be understood in relation to both sex work and the broader Cambodian sexual culture within which these relationships are embedded.
\end{abstract}

\section{Keywords}

female sex workers; condoms; sexually transmitted infections; HIV; Cambodia

(C) 2013 Taylor \& Francis

*Corresponding author. Lmaher@kirby.unsw.edu.au.

John Kaldor, Serey Phal Kien, Lisa Maher, Tooru Nemoto, Kimberly Page, Joel Palefsky, Vonthanak Saphonn and Mean Chhi Vun are the members of Young Women's Health Study Collaborative. 


\section{Introduction}

\section{Condom use in sex work: A Cambodia success story}

Within the Southeast Asian region, Cambodia's response to the HIV epidemic is seen as a success story (Yaşar 2010). Between 2001 and 2005 population prevalence dropped from $2.0 \%$ to $1.6 \%$ (Saphonn et al. 2005, National Center for HIV/AIDS, Dermatology and STD 2006), with the most recent national prevalence estimated at $0.9 \%$ (National Center for HIV/ AIDS, Dermatology and STD 2007). Female sex workers (FSWs) have consistently had the highest HIV prevalence among all groups in Cambodia (National Center for HIV/AIDS, Dermatology and STD 2006). At its height in 1996, HIV prevalence in this population was $45.8 \%$; by 2006, it was down to $14.0 \%$ (Couture et al. 2011). The success in slowing the epidemic among FSWs has been attributed largely to the $100 \%$ Condom Use Programme (100\% CUP) implemented nationally by the Cambodian government in 2001. This programme required condom use in $100 \%$ of penetrative sex in all sex work venues; venue owners and managers had to register FSWs and send them for monthly sexually transmitted infection (STI) examinations (World Health Organization [WHO] 2004). Sanctions for nonadherence - which included evidence of FSWs receiving positive STI tests or failing to offer condoms to an undercover police officer - included closure of venues (Marten 2005). Since the introduction of the programme, consistent condom use reported by brothel-based FSWs and their clients increased from 78\% in 2003 (Wong et al. 2003) to 99\% in 2007 (National Center for HIV/AIDS, Dermatology and STD 2008).

The 100\% CUP has not been universally successful and HIV prevalence among FSWs working in entertainment venues has been uneven compared to that among brothel-based FSWs. National surveillance suggests an overall downward trend among entertainmentbased FSWs: 18.4\% in 1998 and 11.7\% in 2003 (National Center for HIV/AIDS, Dermatology and STD 2006). However, a number of other studies suggest pockets with high prevalence, including $26 \%$ in a study of young women involved in beer promotion in the city of Battambang (Kim et al. 2005) and $23 \%$ in our study of young women involved in the entertainment sector in Phnom Penh (Couture et al. 2011). Behavioural Surveillance Survey (BSS) data indicate high consistent condom use among entertainment-based FSWs: $83 \%$ in 2007 and 2010 (National Center for HIV/AIDS, Dermatology and STD 2008, 2010).

\section{Condom use by FSWs in their non-commercial sexual relationships}

While impressive increases in condom use have been achieved in commercial sexual relationships, there has been little change in condom use between FSWs and their noncommercial casual partners (Wong et al. 2003, Sopheab et al. 2008). Between 2003 and 2007 consistent condom use remained high for sex with clients (direct FSWs 94\% and indirect FSWs 83\%) but much lower for sex with non-commercial partners (direct FSWs $52 \%$ and indirect FSWs 54\%) (National Center for HIV/ AIDS, Dermatology and STD 2008). The most recent BSS (National Center for HIV/AIDS, Dermatology and STD 2010) found that consistent condom use with sweethearts was $56 \%$. Other studies have reported 52\% (Population Services International 2007), 38\% (Sopheab et al. 2008) and 20.6\% (Couture et al.2011).

Consistent condom use between FSWs and their non-commercial partners has proved an intractable issue across the world (Wang et al. 2007, Mai et al. 2008, Stoebenau et al. 2009). Explaining low condom use with non-commercial partners has centred largely on the incompatibility of condoms and intimate relationships due to women's involvement in sex work. The practices sex workers enact during sex work can 'profoundly disrupt the special characteristics of intimate sexual relationships' (Warr and Pyett 1999, p. 300). To preserve the uniqueness of their private relationships, FSWs enact strategies to distance themselves 
'from their labor, to treat the sexual activity as "work" (Bernstein 2007, pp 189-191). This means that they exclude some practices from sex work such as kissing or caressing that are symbolic of intimacy, and enact others such as using condoms (Varga 1997, Warr and Pyett 1999, Wojcicki and Malala 2001, Sanders 2002, Deering et al. 2011). In this way, condoms become associated with sex work and problematic in private relationships.

Research conducted in Cambodia has rarely drawn on explanations from women protecting the specialness of their private relationships or creating public/private boundaries. Indeed, while many epidemiological studies lament the low rate of consistent condom use in noncommercial relationships, they offer no explanation for it (Sopheab et al. 2003, Kim et al. 2005, Gorbach et al. 2006) or blame the failure of interventions targeted at condom use in commercial sex (Sopheab et al. 2008). A qualitative study of female factory workers engaging in sex work argued that sentiments evoked by male non-commercial partners such as 'if we love each other' and promises of marriage posed a barrier to condom use between FSWs and their sweethearts (Nishigaya 2002). This explanation is one more commonly seen in literature unrelated to commercial sex. This work has consistently demonstrated that condom use in committed relationships can be problematic because it suggests a lack of trust (Marston and King 2006) or implies that a partner's STI status is suspect. Thus, condom-free sex is symbolic of trust and commitment (Hillier et al. 1999, Marston and King 2006). It is surprising that common explanations for low condom use in private relationships are so rarely drawn on to understand low condom use among FSWs and their non-commercial partners. While research does recognise that FSWs have sexual partners other than their commercial partners (Stoebenau et al. 2009), these relationships seem to have a different status than private relationships within the broader sexual culture in Cambodia. It is notable, for example, that while many epidemiological studies of sex work in Cambodia report that a significant proportion of FSWs are married, these studies rarely report condom use with husbands.

\section{Condom use by FSWs in sweetheart relationships}

Most surveillance and epidemiological studies, including the Cambodian government's BSS, define sweethearts as non-commercial partners (Sopheab et al. 2003, Gorbach et al. 2006). Others make a distinction between husbands and sweethearts - 'non-commercial, nonmarital sexual relationship that possesses a certain degree of affection and trust from at least one partner' - and casual partners - 'non-paying partner other than the sweetheart with whom women neither are married nor living' (Sopheab et al. 2003, pp. 3-4). This definition of a sweetheart as simply a noncommercial partner, and indeed the very nature of the distinction between commercial and non-commercial, has been complicated by qualitative research in Cambodia (see, for example, Marten 2005). A study of female garment workers involved in direct sex work or discretionary commercial sex (sleeping with men whom they met at entertainment venues) found that women with less autonomy over whom they had sex referred to their clients as 'guests' (Nishigaya 2002). Women with more autonomy, such as beer promoters, referred to their clients as sweethearts. While 'guests' provided women with money for sex, 'sweethearts' were a 'more intimate regular relationship, [they] usually also involve financial support' (Nishigaya 2002, p. 36); that is, sweethearts may not be directly exchanging sex for money but these are often transactional relationships. Clear distinctions cannot be drawn between client/ customer/guest, boyfriend and sweetheart on the basis of the exchange of cash.

Problems with the boundary between commercial and non-commercial sex partners are not limited to sex work research in Cambodia (Stoebenau et al. 2009). Research with FSWs in China found that the distinction made by women was often very subtle; 'boyfriend' could mean a purely non-commercial relationship, a transactional relationship, a current client or previous client (Chapman et al. 2008). Slippage between the categories of commercial and 
non-commercial and, in particular, the ambiguity of the concept 'sweetheart' was widespread in our own data. This slippage - or flexibility - is not reflected in epidemiological studies on condom use.

Regardless of the way that sweetheart is defined, we know that having a 'sweetheart' is a common experience among FSWs in Cambodia and that condom use with sweethearts is low. The 2007 BSS reported that $45 \%$ of direct FSWs and 56\% of indirect FSWs had a sweetheart (Gorbach et al. 2006). In the 2010 BSS, 48\% of entertainment workers (not all of whom are FSWs) had a sweetheart in the past year and consistent condom use was low: 56\% reported using a condom the last time they had sex with a sweetheart (National Center for HIV/AIDS, Dermatology and STD 2010). An earlier study of brothel-based FSWs found that $58 \%$ had a sweetheart in the past year (Sopheab et al. 2008); 25\% reported consistent condom use with a sweetheart.

The reports of the 2007 and 2010 BSS called for more innovative approaches to increase condom use within non-commercial relationships, including specifically 'sweethearts' (National Center for HIV/AIDS, Dermatology and STD 2010). Our aim in this paper is to understand when and why condoms are used or not used in sexual interactions involving women who are sex workers. In any sexual encounter, condom use is 'not a neutral action. It implie(s) specific relational meanings' (Graffigna and Olson 2009, p. 796). These meanings have consequences for whether condoms are or are not used in a specific encounter and in future encounters. The way FSWs act in a particular sexual encounter will be based on the meaning that the sexual encounter and condoms have for them. We are drawing here on Symbolic Interactionism (Blumer 1969), a theoretical perspective that calls on us to look closely at situations - interactions between FSWs and their partners - as the specific contexts in which meaning is created and modified. We do this by exploring FSWs' accounts of negotiating condom use with a range of sexual partners: clients, husbands and boyfriends/ sweethearts (sexual interactions that are neither noncommercial nor commercial).

\section{Methods}

The Young Women's Health Study (YWHS) was a prospective observational study of young women engaged in sex work in Phnom Penh in 2007 to 2010 (Couture et al. 2011, 2012, Maher et al. 2011a, 2011b). As part of YWHS, we conducted 33 in-depth interviews with young women (15 to 29 years old) engaged in sex work in a range of different venues including brothels and entertainment establishments, and on a freelance basis in streets, parks and private apartments in Phnom Penh. Participants were recruited through direct approaches by staff of the community partner, the Cambodian Women's Development Association (CWDA), during neighbourhood-based outreach visits and by referrals from previous participants. Individual interviews were conducted in 2009 in CWDA offices, the Cambodian Prostitutes Union Women's Room and in participants' homes. Interviews were conducted in Khmer by trained interviewers under the supervision of two medical anthropologists, including a Cambodian national, and took between 40 minutes and two hours to complete.

Interviews were digitally recorded and transcribed verbatim in Khmer. Transcripts were checked for accuracy against the recordings before being translated into English. Data were analysed in both Khmer and English using an inductive approach informed by Grounded Theory (Strauss and Corbin 1990). Interview narratives were read and reread and emerging themes discussed and refined to develop an initial coding scheme. Data were then formally coded in parallel by two researchers using both open and axial coding to clarify and consolidate initial themes (Ezzy 2002). 


\section{Results}

\section{Regular and casual clients}

Most commercial sexual transactions involved the use of condoms. Women in our study wanted to use condoms; they actively constructed commercial sexual encounters as risky situations, and explicitly represented them in this way to clients. They described being afraid of disease and pregnancy and using condoms to protect themselves. Women described various strategies to enact this desire for condom use. Condom use was often contested by clients (but not always unsuccessfully).

Successful negotiation-Three negotiation strategies were used to encourage clients to use a condom: fear arousal, sweet talk and no condom equals no sex. The first involved appealing to a client's concern for his own health, either by making explicit reference to disease and the consequences for the client's health or by appealing to a client's sense of responsibility to their family. In the fear arousal strategy, women framed themselves, or sex workers in general, as the source of threats to health and family. They did not describe using their own HIV status as part of this strategy. While we did not ask women about their HIV status during the course of the interviews, many had been tested as part of the Young Women's Health Study (Couture et al. 2011), and several chose to disclose their status. The face sheet for the current study also asked about HIV testing, with $64 \%$ of women reporting being tested in the last 12 months, 9\% last testing more than 12 months ago and $27 \%$ never having had an HIV test, indicating that most women were aware of their HIV status:

If the customer does not use the condom with me, I will give him the reason that I have sex with many men a day and even I myself don't know if I have any disease symptom, and I have only myself and you have your wife and children. If you don't use the condom with me, the result can happen on your wife and your kids. They may listen to my reasons and may use condom with me. (Mealea, 23-year-old woman)

I can negotiate with customers. I would say that I am a sex worker so I am not good at it and I have many sex partners so they had better not be careless with me. (Srey Pich, 26-year-old woman)

While this fear arousal approach made a client's vulnerability salient, it also reinforced existing stereotypes of sex workers as vectors of infection (Rosenthal and Oanha 2006), and rendered other areas of risk less visible. A similar kind of fear arousal tactic has been described by others (Wong et al. 2003). Women repeatedly described drawing on their superior knowledge of HIV and STIs, gained through sex work, in the negotiation of condom use. This strategy has been reported among FSWs in other parts of Asia (Wong et al. 1994, Basuki et al. 2002, Marten 2005):

I said that though body is fat but we cannot see it [HIV] so he must use condom. I further said that I am not sure if you or me who have it, so it is better to use condom so that we can be happy today and forever. (Chenda, 28-year-old woman)

A related strategy involved the use of gentle persuasion to couch the dire health warnings described above. Consoling or sweet talk has been reported by FSWs in Cambodia (Marten 2005) and other parts of Asia (Wong et al. 1994):

We need to console him. To console him with sweet word. I will say 'Darling, you need to use condom because you do not trust me and I also do not trust you. So, you need to use condom'. When we say like that, they would think they do not trust us and we also do not trust them so they have to use condom. (Cheata, 18-year-old woman) 
When the alcohol gets in, he always requests me not to use condom...

[C]onsolation is very important for a drunk man. If he does not want to use condom with me and I am against him with bad words, it will cause problems, so consolation can make him calm. (Srey Mao, 27-year-old woman)

A third strategy described by women was to refuse - or threaten to refuse - to have sex (no condom equals no sex):

My solution is that if they don't use condom, I won't sleep with them. (Any, 20year-old woman)

Some customers tried to force me not to use condom and I replied them that first of all, I am afraid of having HIV and secondly I am afraid of getting pregnant. I then refuse to go with them. (Bophha, 24-year-old woman)

Unsuccessful condom negotiation-Women reported having sex without a condom after telling us they preferred protected sex - for three reasons: economic inducement by clients, the fear of or actual violence by clients, and client or sex worker intoxication with alcohol and/or other drugs, primarily amphetamine-type stimulants (ATS). We have explored the role of ATS use by FSWs elsewhere (Maher et al. 2011b) and concentrate here on client actions that act to persuade or force FSWs not to use condoms when they have expressed a desire to use them. Insisting on condoms could mean losing a paying client, something that had to be balanced against the economic needs that drove participation in sex work in this context:

Some clients asked not to use condom. They pay if we agree. (Rumduol, 27-yearold woman)

Because they give us lot of money, they said that they don't need to use condom. [...] Because I need money to support my parents for living and to support my siblings to go to school. (Channy, 19-year-old woman)

Violence and the fear of violence, including forced sex, were common reasons cited by women in our study for not using condoms:

They hit and forced us not to use condom but I have to use it. (Cheata, 18-year-old woman)

I always use condoms, except when the client is too drunk. I cannot get away from his hands. So, he uses force to catch us. Sometimes, he suffocates me in the bathroom. Under such circumstances, I can [have] sex without condoms with him. He even beats us. (Rumduol, 27-year-old woman)

Experiences of violence were far from uncommon in our study reflecting the experience of FSWs across Cambodia. A 2006 study reported that $75 \%$ of brothel-based workers and $44 \%$ of street-based FSWs had been beaten by their clients in the preceding year, $87 \%$ and $57 \%$ reported being raped by a single client, and $80 \%$ and $55 \%$ by more than one person (United States Agency for International Development [USAID] 2006). Women in our study who worked as street-based sex workers appeared to be more vulnerable to violence and forced condom non-use:

They took me by car to a guesthouse and they force me to have sex with four other men. [Do you know if they used condoms?] No. Not used condom because it was a force. (Srey Mao, 27-year-old woman)

Client intoxication (alcohol or ATS) was a situational feature of commercial sex identified by many participants. Alcohol intoxication was nearly universal, particularly when sex was transacted in bars and restaurants. Challenges to condom use were more common among 
intoxicated clients and the strategies that FSWs typically employed to negotiate condom use, such as appeals to client health and sweet talk, were less effective in the context of client intoxication:

Some customers listen to me and do as what I told but some drunk customers do not. (Srey Sor, 25-year-old woman)

The increased potential for violence in these contexts meant that women were often unable to insist on condom use:

When customer is drunk and he brings me outside. Sometimes when he is drunk, he does not use condom but I told him to use it. If customer does not agree (to use condom) I can't force him. Because customer is too much drunk so he can't use condom. I used to explain him but he denied and did not want to use condom. They think that using or not using condom is the same. If I explain him and he does not agree, I don't know what to do ... because he is too much drunk and it is useless to talk. So, I have to follow him. (Davy, 20-year-old woman)

\section{Husbands}

Women in our study made a clear distinction between non-commercial partners (husbands) and clients; condoms were always used with clients and rarely with husbands:

I don't use with everyday partner, but I always use with customers. (Nath, 23-yearold woman)

In the following extract we can see the construction of the commercial interaction as risky posing a threat of disease - while the marital relationship was defined as a place of safety from this threat:

[In what relation don't you use condom?] I am afraid of getting disease, and getting pregnant. [So, do you always use condom with customers?] Yes, I use condom. [Don't you use condom with your regular customers?] Although they are regular customers, I still use condom because I am afraid of disease, afraid of HIV the most. [How about husband?] Not with husband. [Why don't you use condom with him?] Because he is my husband; he will not find other girls. [Do you trust him?] I do. I have lived with him for years, I know. (Leak, 23-year-old woman)

Because the participant had associated condoms with risk management, they were deemed unnecessary here. The absence of a condom was explained by the construction of the relationship as trustworthy and properly marital ('because he is my husband' is presented as a self-explanatory reason for not using a condom) and her husband as a faithful man ('he will not find other girls'). However, few women gave these straightforward accounts of condoms being incompatible with their relationship. The more dominant account was of condom-free sex, where women wanted to use condoms but their husbands refused:

My husband wants to have a child, so he does not use condom. [Have you ever negotiated with him (about using condoms)?] I told him to use condoms as I did not want to have baby, but he denied. He said that if I force him to use condom it means that I don't love him. (Srey Mom, 20-year-old woman)

My husband sometimes uses condom and sometimes not. [Why did you decide not to use condom with your husband?] I asked him to wear the condom, but he refused. Sometimes he wears it only when feels good. [Did you explain him?] I explained him but he said that if I carry HIV/AIDS, we will die together. I use condom with every customer. (Srey Sor, 25-year-old woman) 
While these women saw condoms as a practical way to protect themselves and others from pregnancy and disease transmission, their husbands evoked the more symbolic meaning of condoms as indicating a lack of connection and intimacy, and not allowing the relationship to be properly marital (e.g. producing children). For Srey Sor's husband, condom was the antithesis of love, while dying as a couple was symbolic of togetherness.

\section{Boyfriends and sweethearts}

The third type of sexual partner was marked by considerable ambiguity. As we foreshadowed, these relationships were neither simply commercial nor simply noncommercial. They almost all featured some kind of transaction, either direct payment or support for living expenses, gifts, etc. Women spoke about them in terms of love or trust, and these partners were referred to as boyfriends or sweethearts. In general, when women talked about boyfriends, condom use was not consistent, and when they talked of sweethearts, condom use was rare. Situations in which women did use a condom tended to be defined in a similar way to commercial interactions: the absence of trust (faithfulness) and the threat of disease:

The reason that I use condom is that boyfriend has never been faithful to me. Far from me, he will go for other woman. He changes partner just like me. (Kannitha, 20-year-old woman)

Although he is my boyfriend, I ask him to use condom because we don't trust each other and afraid of disease transmission. [If your partner does not agree to use condom, how do you negotiate with him?] If he does not use, I will not sleep with him too. We cannot know them well. [How do you talk to him?] I need to console him about the matter that we don't trust one another, so only using condom can make us stay together. (Sophea, 24-year-old woman)

In both extracts above, the situation was defined in terms of risk and risk management. Women wanted to use a condom as a way to protect themselves, and as we saw with clients, they actively negotiated and used strategies such as sweet talk and no condom equals no sex. Women did not talk about the failure of these strategies, suggesting that like commercial situations, women had rights to negotiate. The more dominant account in our interviews was of condom-free sex with boyfriends and sweethearts. With only one exception, none expressed a desire to use condoms nor described a partner refusing. For some women, the nature of the relationship was sufficient to explain the lack of condoms:

[How about with your boyfriend and sweetheart you are living with every day?] No, not that. [You don't use condom?] Not use condom. [Why don't you use?] I love as my husband. [Do you trust him?] Yes, I do. (Nath, 23-year-old woman)

Other women were explicit about what precluded the need for condoms: mutual understanding, familiarity over a long period of time and trust. For example:

We used to be together often and we understand each other's heart. We don't need to use condom because we have known each other for a long time. (Roth, 19-yearold woman)

In the next extract, we again see talk of love and trust, but from the perspective of the partner:

[Why did you decide not to use condom with him?] Because he trusts me. He has no other partner and he loves me. (Srey Noch, 24-year-old woman)

There is an interesting paradox here. Srey Noch suggested that she does not use condoms because her partner loves and trusts her, and he does not have any other partners. But as a 
sex worker, Srey Noch has multiple partners. The absence of sexual faithfulness in sweetheart relationships seemed not to produce a need for condoms:

No I don't use condom with sweetheart. [...] Because I love him honestly from my heart and I think he also loves me, but faithful or not, I don't know. [...] I don't use condom. No need to use condom because he is my sweetheart [...] I don't use. I don't want to use. (Kannitha, 20-year-old woman)

For Kannitha, the absence of the condom is symbolic of love. Even though the situation (relationship) could be understood in terms of risk - there is uncertainty around her partner's faithfulness - she defines it in terms of intimacy and love, and this meaning prevails.

\section{Discussion}

Our findings around condom use and non-use in commercial relationships echo the literature: while consistent condom use is high, FSWs reported occasions when condoms were not used. Where a condom is available and a FSW wants to use one, the most common explanations for condom non-use in Cambodia are economic necessity (clients offering more money), fear of or actual violence, FSWs' drug or alcohol intoxication eroding behavioural intentions or FSWs not having the skills to negotiate condom use (Wong et al. 2003, Maher et al. 2011b). Again, our findings do not suggest anything different.

Through talk of fearing disease and pregnancy and using condoms to protect themselves, women constructed commercial sexual encounters as risky situations. They reported characterising them in this way to their clients. There was much uncertainty and little trust, a state of affairs that demanded management through careful negotiation (e.g. sweet talk), education (e.g. about HIV and the lack of visible symptoms) and assertion of their rights to self-care (e.g. refusing sex). It was clear that women had particular rights and expertise in these situations; they could claim to know about HIV and other STIs. Their negotiations around condoms were generally accepted by their sexual partners/clients (this was demonstrated by clients engaging in the negotiation). According to women in our study, the occasions where condoms were not used were ones where a client denied their autonomy and forced them to have sex without a condom.

In contrast, our data on husband-wife relationships did not resonate with the literature in the way we expected (for example, Warr and Pyett 1999): some women did want to use condoms but their husbands refused. These women characterised their marital sexual interactions as risky to themselves - the threat of an unwanted pregnancy - and to their partners - the threat of disease transmission. For husbands however, the symbolic meaning of condoms as preventing connection and intimacy prevailed. Paradoxically, and problematically for HIV prevention, for some husbands a condom appeared to symbolise a lack of care for the other, rather than a symbol of care for each other. We saw this in one husband's re-casting of risky behaviour (condom-free sex) that might transmit HIV as romantic, a symbol of the couple's togetherness. It is possible then that it is husbands who are engaged in the work to construct the relationship with their sex worker partner as special and different to sex work (Warr and Pyett 1999).

Given the strategies women described to actively negotiate condom use with clients, the absence of active negotiation with husbands was striking. Indeed, where women suggested they had said they wanted to use condoms but their husbands had decided not to, there was no discussion. Although these women are highly skilled sexual negotiators, practised in managing intoxicated and, at times, violent clients, they did not deploy these skills in negotiating condom use with their husbands. The active and assertive position women described taking in a sex work context may be untenable in these relational contexts. There 
is an important distinction here: for some women, a condom was not incompatible with their marital relationship but the negotiation strategies they successfully deployed in sex work seemed to be. We wonder if negotiating condom use with husbands was problematic because it was seen as inappropriate behaviour for a wife. That is, the rights to negotiate conveyed by the commercial sex work context were absent in the marital relationship, which is understood within a traditional cultural framework. Research on the use of contraception among Cambodian women supports this hypothesis (Samandari et al. 2010).

When discussing sweetheart and boyfriend relationships, women often presented condoms as simply unnecessary in a relationship that was defined or constructed as a 'boyfriendgirlfriend' or 'husband-wife' relationship. Women did not always say what led the relationship to be seen in this way; they simply drew a connection between condom non-use and husbands and wives. We expected to see an explanation of this kind about actual husband-wife relationships; however, this did not emerge in the data. In their work with Chinese FSWs, Chapman and colleagues argue that 'it is clearly the status that one gives to the relationship that is important in determining condom use rather than its nature' (Chapman et al. 2008, p. 295). If this is true, then how can we explain some women wanting to use condoms with their husbands but not with their non-marital non-commercial partners? Within our Symbolic Interactionist framework, condom use or non-use is not determined by relationship status, but is part of the work that produces the status of the relationship. Using a condom with their husband may be unproblematic for some FSWs because the relationship's status has already been established and recognised publically through a marriage ritual (although not necessarily sufficiently for husbands). Whereas the boyfriend and sweetheart relationship is liminal, and there is still much symbolic work to be done to resolve the status of these relationships, especially where the relationship began as commercial. Thus, the condom plays a central symbolic role in establishing the meaning or status of an ambiguous relationship, or a relationship in transition. There is some evidence from the literature to support our argument; a study drawing on Cambodia's BSS discusses how older FSWs cultivate regular clients or sweethearts as a way to exit sex work, thus 'a change in condom use behaviour represent a prelude to an exit out of sex work... because sex without condoms is often interpreted as an experience of intimacy or trust' (Gorbach et al. 2006, p. 246). Research suggests that clients who refuse condoms often frame their relationships with FSWs as similar to their relationships with their wives (Basuki et al. 2002). That is, for clients, unprotected sex may symbolise intimate marital sex (Lyttleton 2000). So while trust and intimacy are associated with condom use, as suggested repeatedly in the literature, this is not as straightforward as it seems: condom-free sex produces a sense of intimacy rather than simply indicating it. The 100\% CUP is clearly implicated here; by powerfully associating condoms with risk, it has reinforced the symbolic value of the condom in the broader culture.

\section{Conclusion}

In this paper, we have sought to understand why condoms are not used in sexual encounters involving FSWs. By looking at the way condom use is negotiated across relationship types, rather than focusing on one relational context, as many studies do, we contrasted the different meanings of sexual interactions and condom use to women and their partners. We argued that to understand the failure to see any change in condom use in the non-commercial sexual relationships of FSWs, we need to see FSWs' relationships both in relation to sex work (the conventional approach) and the broader Cambodian sexual cultural within which these relationships take place. We demonstrated that knowledge (e.g. of HIV risk) and skills (e.g. condom negotiation) are not easily transferred between sexual contexts. Women (and their partners) might abandon condoms in order to change the status of the relationship, to symbolically mark ambiguous relationships as intimate. Our data suggested that in many of 
these non-commercial and non-marital relationships, there was little or no expectation of sexual faithfulness. While this was construed as risky and necessitating condoms in one context (commercial sex), it was not here. That is, understandings of risk are socially constructed and highly context specific (Adam et al. 2000). Those designing HIV prevention programmes need to be cognisant of complex interpersonal, social and cultural factors. Attempts to address condom use in non-commercial relationships need to be nuanced rather than a simple message that all relationships are risky; recognise that all private relationships are not the same; and engage directly with the complex and often contradictory meanings of condom use in the broader sexual culture.

\section{Acknowledgments}

We are indebted to the women who participated in the study and grateful for the privilege of working with them. We acknowledge the efforts of the CWDA research team, especially Chan Dyna, Tony Masy, Serey Mealy, Ly Vina, Chhuon Minea, Keo Sichan, Hun Phanna, Sok Phearum, Prak Saban, Khun Saveth, Ni Say, Sok Sreyleak and A Tyna. This study received financial support from the following National Institutes of Health (NIH) grants: U01AI0154241, 1R21 DA025441 and 1R01NR010995. Lisa Maher is supported by a National Health and Medical Research Council Senior Research Fellowship, and Marie-Claude Couture is supported by a Canadian Institutes of Health Research Postdoctoral Fellowship. The Kirby Institute is affiliated with the Faculty of Medicine, University of New South Wales, and is funded by the Australian Government Department of Health and Ageing. The views expressed here do not necessarily represent the position of the Australian Government or the Cambodian Ministry of Health.

\section{References}

Adam, B.; Beck, U.; Van Loon, J., editors. The risk society and beyond: critical issues for social theory. London: Sage; 2000.

Basuki E, Wolffers I, Deville W, Erlaini N, Luhpuri D, Hargono R, Maskuri N, Suesen N, van Beelen $\mathrm{N}$. Reasons for not using condoms among female sex workers in Indonesia. AIDS education and prevention. 2002; 14(2):102-16.10.1521/aeap.14.2.102.23901 [PubMed: 12000229]

Bernstein, E. Temporarily yours: intimacy, authenticity, and the commerce of sex. Chicago: The University of Chicago Press; 2007.

Blumer, H. Symbolic interactionism: perspective and method. Berkley: University of California Press; 1969.

Chapman J, Estcourt CS, Hua Z. Saving 'face' and 'othering': getting to the root of barriers to condom use among Chinese female sex workers. Sexual health. 2008; 5:291-298.10.1071/SH07057 [PubMed: 18771646]

Couture MC, Evans JL, Sothy NS, Stein ES, Sichan K, Maher L, Page K. Correlates of amphetaminetype stimulant use and associations with HIV-related risks among young women engaged in sex work in Phnom Penh, Cambodia. Drug and alcohol dependence. 2012; 120(1-3):119-126.10.1016/ j.drugalcdep.2011.07.005 [PubMed: 21820251]

Couture MC, Sansothy N, Sapphon V, Phal S, Sichan K, Stein E, Evans J, Maher L, Kaldor J, Vun MC, Page K. Young women engaged in sex work in Phnom Penh, Cambodia, have high incidence of HIV and sexually transmitted infections, and amphetamine-type stimulant use: new challenges to HIV prevention and risk. Sexually transmitted diseases. 2011; 38(1):33-39.10.1097/OLQ.

0b013e3182000e47 [PubMed: 21085056]

Deering KN, Bhattacharjee P, Bradley J, Moses SS, Shannon K, Shaw SY, Washington R, Lowndes CM, Boily MC, Ramesh BM, Rajaram S, Gurav K, Alary M. Condom use within non-commercial partnerships of female sex workers in southern India. BMC public health. 2011; 11(suppl. 6):S11.10.1186/1471-2458-11-S6-S11 [PubMed: 22376171]

Ezzy, D. Qualitative analysis: practice and innovation. Sydney: Allen \& Unwin; 2002.

Gorbach PM, Sopheab H, Chhorvann C, Weiss RE, Vun MC. Changing behaviors and patterns among Cambodian sex workers: 1997-2003. JAIDS Journal of Acquired Immune Deficiency Syndromes. 2006; 42(2):242-247.10.1097/01.qai.0000214817.03411.80 
Graffigna G, Olson K. The ineffable disease: exploring young people's discourses about HIV/AIDS in Alberta, Canada. Qualitative health research. 2009; 19(6):790-801.10.1177/1049732309335393 [PubMed: 19366859]

Hillier L, Harrison L, Bowditch K. Neverending love' and 'blowing your load': the meanings of sex to rural youth. Sexualities. 1999; 2:69-88.10.1177/136346099002001004

Kim AA, Sun LP, Chhorvann C, Lindan C, Van Griensven F, Kilmarx PH, Sirivongrangson P, Louie JK, Leng HB, Page-Shafer K. High prevalence of HIV and sexually transmitted infections among indirect sex workers in Cambodia. Sexually transmitted diseases. 2005; 32(12):745751.10.1097/01.olq.0000175384.44106.be [PubMed: 16314771]

Lyttleton, C. Endangered relations: negotiating sex and AIDs in Thailand. Bangkok: White Lotus; 2000.

Mai TTT, Le CL, Nguyen TL. Factors associated with inconsistent condom use among female sex workers in Nha Trang, Vietnam. Asia-Pacific journal of public health. 2008; 20(4):370 378.10.1177/1010539508322485 [PubMed: 19124331]

Maher L, Mooney-Somers J, Phlong P, Couture MC, Stein E, Evans J, Cockroft M, Sansothy N, Nemoto T, Page K. the Young Women's Health Study Collaborative. Selling sex in unsafe spaces: sex work risk environments in Phnom Penh, Cambodia. Harm reduction journal. 2011a; 8(1): 30.10.1186/1477-7517-8-30 [PubMed: 22099449]

Maher L, Phlong P, Mooney-Somers J, Keo S, Stein E, Couture MC, Page K. Amphetamine-type stimulant use and HIV/STI risk behaviour among young female sex workers in Phnom Penh, Cambodia. International journal of drug policy. 2011b; 22(3):203-209.10.1016/j.drugpo. 2011.01.003 [PubMed: 21316935]

Marston C, King E. Factors that shape young people's sexual behaviour: a systematic review. The Lancet. 2006; 368(9547):1581-1586.10.1016/S0140-6736(06)69662-1

Marten L. Commercial sex workers: victims, vectors or fighters of the HIV epidemic in Cambodia? Asia Pacific viewpoint. 2005; 46:21-34.10.1111/j.1467-8373.2005.00257.x

National Center for HIV/AIDS, Dermatology and STD. Annual report 2006. Phnom Penh: Ministry of Health; 2006.

National Center for HIV/AIDS, Dermatology and STD. Report of consensus workshop HIV estimates and projection for Cambodia. Phnom Penh: Ministry of Health; 2007. p. 2006-2012.

National Center for HIV/AIDS, Dermatology and STD. Behavioural sentinel surveillance 2007. Phnom Penh: Ministry of Health; 2008.

National Center for HIV/AIDS, Dermatology and STD. Behavioural sentinel survey (BSS) 2010. Phnom Penh: Ministry of Health; 2010.

Nishigaya K. Female garment factory workers in Cambodia: migration, sex work and HIV/AIDS. Women \& health. 2002; 35(4):27-42.10.1300/J013v35n04_03 [PubMed: 12216990]

Population Services International. HIV/AIDS TRaC study evaluating condom use among karaoke women with sweethearts in Phnom Penh and Siem Reap Second round. Washington, DC: Population Services International; 2007.

Rosenthal D, Oanha TT. Listening to female sex workers in Vietnam: influences on safe-sex practices with clients and partners. Sexual health. 2006; 3(1):21-32.10.1071/SH05040 [PubMed: 16607971]

Samandari G, Speizer IS, O'Connell K. The role of social support and parity on contraceptive use in Cambodia. International perspectives on sexual and reproductive health. 2010; 36(3):122131.10.1363/3612210 [PubMed: 20880797]

Sanders T. The condom as psychological barrier: female sex workers and emotional management. Feminism \& psychology. 2002; 12(4):561.10.1177/0959353502012004016

Saphonn V, Parekh BS, Dobbs T, Mean C, Bun LH, Ly SP, Heng S, Detels R. Trends of HIV-1 seroincidence among HIV-1 sentinel surveillance groups in Cambodia, 1999-2002. Journal of acquired immune deficiency syndrome. 2005; 39(5):587-592.

Sopheab H, Gorbach PM, Gloyd S, Leng HB. Rural sex work in Cambodia: work characteristics, risk behaviours, HIV, and syphilis. Sexually transmitted infections. 2003; 79(41):e2.10.1136/sti. 79.4.e2 [PubMed: 12902610]

Sopheab H, Morineau G, Neal JJ, Saphonn V, Fylkesnes K. Sustained high prevalence of sexually transmitted infections among female sex workers in Cambodia: high turnover seriously challenges 
the $100 \%$ condom use programme. BMC infectious diseases. 2008; 8(1):

167.10.1186/1471-2334-8-167 [PubMed: 19077261]

Stoebenau K, Hindin MJ, Nathanson CA, Rakotoarison PG, Razafintsalama V. "But then he became my sipa": the implications of relationship fluidity for condom use among women sex workers in Antananarivo, Madagascar. American journal of public health. 2009; 99(5):811-819.10.2105/ AJPH.2007.118422 [PubMed: 19299685]

Strauss, A.; Corbin, J. Basics of qualitative research: grounded theory procedures and techniques. London: Sage; 1990.

United States Agency for International Development USAID. Violence and exposure to HIV among sex workers in Phnom Penh, Cambodia. Washington, DC: United States Agency for International Development; 2006.

Varga CA. The condom conundrum: barriers to condom use among commercial sex workers in Durban, South Africa. African journal of reproductive health. 1997; 1(1):74-88.10.2307/3583277 [PubMed: 10214405]

Wang C, Hawes SE, Gaye A, Sow PS, Ndoye I, Manhart LE, Wald A, Critchlow CW, Kiviat NB. HIV prevalence, previous HIV testing, and condom use with clients and regular partners among Senegalese commercial sex workers. Sexually transmitted infections. 2007; 83(7):534540.10.1136/sti.2007.027151 [PubMed: 17942575]

Warr D, Pyett P. Difficult relations: sex work, love and intimacy. Sociology of health and illness. 1999; 21(3):290-309.10.1111/1467-9566.00157

Wojcicki J, Malala J. Condom use, power and HIV/AIDS risk: sex-workers bargain for survival in Hillbrow/Joubert Park/Berea, Johannesburg. Social science \& medicine. 2001; 53(1):99_ 121.10.1016/S0277-9536(00)00315-4 [PubMed: 11380165]

Wong ML, Archibald C, Roy KW, Goh A, Tan TC, Goh CL. Condom use negotiation among sex workers in Singapore: findings from qualitative research. Health education research. 1994; 9(1): 57-67.10.1093/her/9.1.57 [PubMed: 10146733]

Wong ML, Lubek I, Dy BC, Pen S, Kros S, Chhit M. Social and behavioural factors associated with condom use among direct sex workers in Siem Reap, Cambodia. Sexually transmitted infections. 2003; 79(2):163-165.10.1136/sti.79.2.163 [PubMed: 12690144]

World Health Organization (WHO). Experiences of $100 \%$ condom use programme in selected countries of Asia. Geneva: World Health Organization; 2004.

Yaşar Y. Gender, development, and neoliberalism: HIV/AIDS in Cambodia. Review of radical political economics. 2010; 42(4):528-548.10.1177/0486613410375062 